\title{
The Size of History: Coincidence, Counterfactuality and Questions of Scale in History
}

\author{
Olivier Hekster
}

\begin{abstract}
Historians try to interpret the past by analysing patterns in human behaviour in earlier periods of time. In some ways, that excludes 'coincidence' as a mode of interpretation. Most historians view coincidences as closely related events that lack causal relationship. That type of coincidence does not fit into a historical narrative, because historians tend to focus on causality, action, and consequence. This is noticeably linked to questions of historical scale: the choice for the scale of a specific narrative decides whether certain events are coincidental to the history which is being described, or causal factors within that history. This relation between historical coincidence and the scale of writing history is at the centre of this contribution. It focuses on different trends in writing history, and analyses the possibilities to use 'coincidence' as an interpretative tool in each of them. In doing so, this article discusses counterfactual historical analysis ('what if history'), determinist views of history and their relation to speculative philosophy of history, 'cliodynamics' and 'big history'. It ultimately argues for historical accounts that pay attention to both the large processes that are likely to lead to certain trajectories, and the enormous number of micro-causes that triggered the events as they happened. Coincidence might fall outside of the analysis of (macro-) historians who are looking for a comprehensive view of historical processes, but could still play a proper role in thinking about historical trajectories.
\end{abstract}

\section{Introduction: Coincidence and Comparisons}

Historians try to interpret the past. They do so by analysing patterns in human behaviour in earlier periods of time. In some ways, that excludes 'coincidence' as an interpretative tool. The word 'coincidence', after all, derives from the Latin cum incidere, which means 'happening together'. Most historians take this to imply that coincidences are events that seem closely related but lack a causal relationship. They

\footnotetext{
O. Hekster ( $\square)$

Faculty of Arts, Radboud University, Nijmegen, The Netherlands e-mail: o.hekster@let.ru.nl 
just happen to occur at (roughly) the same time, or in a similar mode. This makes them, at first sight, less suitable as a historical explanatory notion. ${ }^{1}$ This rather negative meaning of the word 'coincidence' in a historical context is best exemplified by the among American historians infamous list of 'creepy coincidences' between Abraham Lincoln and John F. Kennedy. The coincidences in question range from 'the names Lincoln and Kennedy both contain seven letters' to 'both presidents were shot in the head on a Friday before a major holiday'. The challenge to professional historians is then to explain this set of coincidences. Since the sort of similarities assembled on the list can be drawn between any historical figures, these 'coincidences' only amass to 'pseudo-historical demonstrations of data-massaging' (Kern and Brown 2001, p. 534). What lacks is any attempt to explain the (historical) significance of these similarities, meaning that they do not usefully contribute to modes of interpreting past events.

This is not to say that analysing similarities in itself is something that is condemned by modern historians. In fact, comparing and contrasting individuals or societies which seem similar in their structural set-out but have only limited interrelation is one of the methodological starting points of comparative history. By comparing given individuals, institutes or areas, core aspects of specific phenomena can become clearer. But it is tacitly acknowledged that the historical relevance of these similarities needs to be explained, in terms of cause and effect, for them to be useful as a historical term. This can be explicitly contrasted with 'coincidental' similarities, as is clear from a recent overview of the progress of historical scholarship by J.H. Elliott. Elliott reflects on his earlier comparative study of the two seventeenth-century statesmen cardinal Richelieu and the Count Duke of Olivares, in which he noted several similarities between the two, one of the more trivial being that both men were third sons of noble fathers, finding employment in the service of a monarch. 'But', he observes, 'this simple fact suggests one of the problems inherent in comparative history. Are we dealing here with coincidence, or does the similarity point to some wider consideration that is worthy of note?' (Elliott 2012, p. 180; Elliott 1991). Coincidences in themselves, clearly, are not deemed noteworthy.

Both Olivares and Richelieu received an early education for an ecclesiastical career. The death of Olivares' older brother meant that Olivares became head of the family and needed to marry. Unwillingness of Richelieu's older brother Alphonse to become bishop meant that Richelieu would make a career in the church. Elliott describes the developments in their respective families as 'an initial coincidence' but one that 'went on to create a number of similarities', which he does consider 'of obvious significance', such as the influence of neo-Stoic philosophy on their actions as statesmen. He contrasts these to 'other coincidences' that 'may lead to a dead end', although even such 'chance resemblances' can help sharpening the mind (Elliott 2012, p. 180-1). There is clear differentiation here between (if no real definition of) what is deemed relevant for explaining actions and events, and what is

\footnotetext{
${ }^{1}$ For the development leading to the exclusive use of cum incidere as coincidence, see Vogt (2011), pp. 43-66 followed by a discussion of the Greek Tyche.
} 
deemed merely anecdotal, and without explanatory power. Something is either 'a mere coincidence' or, more often encountered within historical scholarship, 'not a coincidence', and therefore relevant.

Coincidence, in this reading, becomes something that does not fit into a historical narrative, mainly because historians, as a very recent Manifesto formulated: 'focus on the question of how: Who did the changing, and how can we be sure they were the agents? These analytics of causality, action, and consequence make them specialists in noticing the change around us' (Guldi and Armitage 2014, p. 14). Notions that happened to happen but (the agency of which) cannot be explained fall outside of such a view of historical analysis. If (human) agency is a core interest, the question of coincidence becomes linked to discussions about the randomness of human behaviour or about free will (see the articles of Weitzel and Rosenkranz, Thijssen and Loy, and Van Elk, Friston and Bekkering in this volume), neither of which cohere easily with the attention (or competence) of most historians.

There is also an aspect of scale involved. Whether a historian interprets something as coincidental to, or a central focus of causality of, events depends somewhat on the historical scope of his or her analysis. The education of historical figures, for example, may explain their historical actions. Few biographers would formulate their protagonist's education as 'mere coincidence', but for a historian who is interested in larger historical trajectories, the education that a single individual happened to have had, and which may explain specific actions that were part of a wider chain of events, has much less explanatory force. In such a reading the definition of historical coincidence becomes almost a matter of taste. To be more precise: the choice for the scale of a specific historical narrative decides whether certain events are coincidental to the history which is being described, or causal factors within that history. This relation between historical coincidence and the scale of writing history is at the focus of this contribution.

\section{Contingency, Causality and Counterfactuality}

As must be clear from the above, there is certainly some space for coincidence as a factor in historical explanation. There is a number of semi-synonyms that feature somewhat more frequently in modern historiography, among which 'accident', 'singular event', 'chance' and 'contingent circumstances' are especially noticeable. The term 'luck' also features, but mainly as a (rather self-effacing) explanation for success in the career trajectory of a particular historian, or as part of cautionary reflections on the ways in which processes which are difficult to influence or trace have influenced historical discoveries. (DuPont Chandler 2004; McClellan III 2005; Cushing 1992). Luck, it seems, can be allowed to have influenced individual historians, but is not explicitly acknowledged as a factor in the historical processes that these historians investigate.

The situation seems different when 'contingency' is mentioned. There is a long-standing strand of historical research that deals with 'turning points', and at 
some of these turning points, in a famous dictum by the great British historian George M. Trevelyan 'history failed to turn'. ${ }^{2}$ The notion that events may have 'failed to turn as expected is to admit the role of contingency, the element of chance -randomness' (Post 2009). This has ultimately led to a flourishing (though not uncontested) strand of historical analysis which is known as 'virtual history' or 'counterfactual history'. The question posed by historians in this form of research is 'what would have happened if events at a certain turning point would have gone marginally differently'. Even before explicit attention to such counterfactuality, this had been an implicit mode of reasoning within scholarly historical works, going back at least to the Roman historian Livy's analysis of how a war between the armies of Alexander the Great and Rome would have played out (Ab Urbe Condita 9.17-19; Morello 2002). Perhaps the most famous example of modern implicit historical use of counterfactuality is the statement by the German historian Eduard Meyer in his Geschichte des Altertums that if the Persians had beaten the Greeks (especially the Athenians) at the battle of Marathon in 490 BC European culture would have developed entirely differently:

Das Endergebniss wäre schliesslich doch gewesen, dass eine Kirche und ein durchgebildetes theologisches System dem griechischen Leben und Denken ihr Joch aufgelegt und jede freiere Regung in Fesseln geschlagen hätte, dass auch die neue griechische Kultur so gut wie die orientalischen ein theologisch-religiöses Gepräge erhalten hätte. ${ }^{3}$

This line of arguing was recognised as 'counterfactual' by Max Weber, who started his career as an ancient historian. Shortly after the publication of Meyer's work, he noted how the argument that the development of European history would have shifted dramatically with a different outcome of the battle at Marathon rested on a series of assumptions. Meyer argued that a Persian victory would have blocked the preconditions for Athenian supremacy, and with it (still according to Meyer) the development of democracy and rationality. Weber showed the analogies that stood at the basis of the argument (Persian behaviour elsewhere), and showed the methodological pitfalls within such a line of argument. Meyer' conclusions were less at stake than his methods, as is clear from the title of Weber's 1905 essay that has become justly famous: 'Objective possibility and adequate causation in historical explanation'. In it, Weber questions

how the attribution of a concrete result to a single 'cause' is ... feasible ... given that ... it is always an infinity of causal factors that brought about the single 'event'.

\footnotetext{
${ }^{2}$ Trevelyan (1918), p. 79. The quote is often contributed to Taylor (1945), p. 71, who describes Germany in the contexts of the revolutions in 1848: 'German history reached its turning-point and failed to turn'.

${ }^{3}$ Meyer (1901), 446: 'The end result would ultimately have been that a Church and a well-developed theological system had brought the Greek life and thought under their yoke, and placed chains on any aspiration to freedom; that the new Greek culture, much like oriental culture, would have had a theological-religious character'.

${ }^{4}$ Weber (1905) with the comments by Ringer (2002). Cf. also Huizinga (1937), p. 137.
} 
The answer is counterfactual reasoning, by which, Weber argued, it becomes possible to conjecturally sort and rank different possible causes. The historian can take various events out of the equation, and then conjecture what the new historical trajectory would be. This makes it possible to see which potential causes would have brought about which effect. Causality and intention are at issue here. The crucial Weberian terms are 'objective probability' and 'adequate causation':

Where an actual result was brought about by a complex of antecedent conditions that made it 'objectively probable', the 'cause' is termed 'adequate' in relation to the 'effect'. Where a causal factor contributed to a historically interesting aspect of an outcome without being 'adequate' in this sense, it may be considered its 'accidental cause' (Ringer 2002, pp. 165-6).

The 'accidental cause' in the Weberian sense is of course not the same as coincidence, but his line of arguing highlights an awareness that developments in history could have gone differently, and that often events that seemed less directly relevant may have had wide-ranging consequences. Noticeably, in Weber's argument a single concrete cause leads to one concrete effect, making it particularly important for him to distinguish between causal and coincidental relations.

There is, in fact, an element of the counterfactual in almost all assumptions of causality. If we argue that one event causes a second event, we also argue that the second event would not have taken place (or at least not in that way) without the first. In that sense, there is little difference between 'true' causes and coincidences, as the coincidence still caused later events to happen. It is here that scale becomes an issue. Historians accept events as a 'true' cause if they fit the size of their narrative interest. If they are too 'small', they are often waylaid as coincidental, if they are too 'big' they become background context. Whether a cause is deemed of the right size depends on what the historian is trying to (re)construct. Within that reconstruction, there are protagonists, turning points and contexts. The scale of the historical trajectory decides which events are too small (coincidental) or too big (background). In that sense, a historical coincidence is a cause (in the counterfactual sense) which is without explanatory force within the chosen narrative framework.

This is an important background to so-called 'what if' history, which tends to focus on causes that seem too small for the historical trajectory which is being analysed - and therefore seem to suggest that coincidence plays a major part in history. Such attention for (single) events that could have gone either way has had numerous advocates in the 20th century. One of the earliest examples of what ultimately grew to be a proper genre of counterfactional history is a collection of essays by professional historians called If It Had Happened Otherwise, which best claim to fame is the inclusion of an essay by Winston Churchill on what would have happened if Lee had won the Battle of Gettysburg. ${ }^{5}$ For much of the remainder of the 20th century these essays were mainly influential on writers of fiction, lying at the base of the genre of 'alternate history/reality'.

\footnotetext{
${ }^{5}$ Squire (1931). Cf. Hacker and Chamberlain (1981), with an overview of early examples of counterfactual history, and now Gallagher (2011).
} 
Yet, some historians also engaged with this line of thinking, and recognised that the ultimate consequence of it would be that 'the course of the world's history depends on accidents'. Notably, the historian and classicist J.B. Bury devoted an essay on contingency, starting with the importance of the shape of Cleopatra's nose. If this nose had not been so attractive, the argument went, Mark Antony would not have been so distracted as to lose the pivotal battle at Actium (31 BC) against the later emperor Augustus. Of course, the 'shape of Cleopatra's nose was rightly conditioned by the causal sequence of her heredity', but since this causal link had nothing to do with causal links determining the politics of Ancient Rome, the 'collision' of these two unrelated sequences, in Bury's view, boiled down to chance: 'the valuable collision of two or more independent chains of causes'. He refines this definition by differentiating between 'pure' and 'mixed' contingencies:

If Napoleon at an early stage in his career had been killed by a meteorite, that would have been the purest of pure contingencies ... The meteorite was completely disinterested in his death. ${ }^{6}$

This emphasis on the role of chance on historical processes led to what has been coined the 'accidental view of history', which opposed notion of historical inevitability (Berenson 1952, 88). It was embraced by, amongst others, the philosopher Isaiah Berlin. In his essay on 'Historical inevitability', he argued strongly for recognition of the role of accidents in history, which he placed in opposition to the (in his thoughts) determinist philosophies of history of Marx and Hegel, to which we will return later in this essay. According to Berlin, explaining human behaviour in terms of causality denied free will, and falsely absolved historians of the task to morally evaluate historical actors: 'to assess degrees of their responsibility, to attribute this or that consequence to their free decision, to set them up as examples or deterrents, to seek to derive lessons from their lives'. Recognising that there are accidents that influence the course of events, and that only these, 'force majeure - being unavoidable - are necessarily outside the category of responsibility and consequently beyond the bounds of criticism' 7

This view of history, and of the role of the historian, was famously opposed by the historian and diplomat E.H. Carr, who took issue with 'Cleopatra's Nose' in his influential What is History. Carr explicitly argued against those who 'pointed out the absurdity of failing to recognise the role of accident in history', singling out Berlin whom he blames for talking nonsense (conceding that he did so 'in an engaging and attractive way') and for flogging 'this very dead horse back into a semblance of life'. Berlin's (and Karl Popper's) opposition to a deterministic outlook in history, with their emphasis on chance, was in Carr's view little more than 'a parlour game with the might-have-beens of history' (Carr 1961, pp. 92-99). The role of the historian is to recognise patterns of historical significance:

\footnotetext{
${ }^{6}$ Bury (1916/1930), pp. 60 (course of history), 61 (chance), 62 (heredity), 67 (Napoleon).

${ }^{7}$ Berlin (1954/2012), pp. 119-190, citing Berenson (p. 119), discussing the importance of moral judgement (pp. 140-142), and discussing force majeure (p. 146).
} 
Just as from the infinite ocean of facts the historian selects those which are significant for his purpose, so from the multiplicity of sequences of cause and effect he extracts those, and only those, which are historically significant; and the standard of historical significance is his ability to fit them into his pattern of rational explanation and interpretation. Other sequences of cause and effect have to be rejected as accidental, not because the relation between cause and effect is different, but because the sequence itself is irrelevant. The historian can do nothing with it; it is not amenable to rational interpretation, and has no meaning either for the past or the present (Carr 1961, p. 105).

For a long time, Carr's criticisms made 'what-if-history' suspect for serious scholars. But counterfactual constructions of historical developments have blossomed as an academic branch of writing history since the publication of Ferguson (1997). Ferguson, like Bury and especially Berlin before him, ultimately tries to take distance from deterministic views of historical processes (Marxism prime amongst them) and aims to show how a limited set of changes, in which contingent factors would have changed crucial outcomes, would have resulted in an almost unrecognisable historical trajectory; a 'virtual history' for the period 1646-1996.

There have, almost inevitably, been counter-reactions, most noticeably by Richard Evans (2014), written at least partly to explain his 'initial, somewhat allergic reaction' (p. xvi) to counterfactuals. Evans argues amongst other that the impression that history could have developed in a radically different way by a combination of minor moments of chance will challenge interest in what really happened, and 'allows historians to rewrite history according to their present-day political purposes and prejudices' (p. 63). Moreover, Evans argues, counterfactual thinking does not, in fact, function well

as a vehicle for overcoming "determinism", in the sense of the prioritization of larger historical forces over smaller, personal, chance, and contingent events and circumstances (Evans 2014, p. 104).

By selecting a finite number of 'alternative outcomes that were at least plausible', counterfactual studies, according to Evans, highlight the importance of forces beyond individual control. Noticeably, Evans' criticism of these 'altered pasts' does not focus on the existence and importance of chance events as such within the functioning of history, but on the assumption that one minor alteration in the historical timeline would cascade towards major changes over a prolonged period of time. In Evans' view, history is not necessarily fixed, but historians should not have the liberty to adapt it as they see fit (Evans 2014, p. 46).

Criticism on counterfactual history is not quite the same as criticism on counterfactual thinking within historical analyses, which is much less disputed. Indeed, the above-mentioned History Manifesto sees historical expertise in counterfactual thinking as an important asset for answering questions of sustainability, and possibly other problems that are acute in modern society (Guldi and Armitage 2014, pp. 31-4, with Booth 2003 and Thompson 2010). Such a use of counterfactual history partly closes the gap between counterfactual history and counterfactual analysis. The latter aims to draw clear distinctions between causal and coincidental relations, but does not suggest alternative trajectories. It also tries to apply counterfactual analysis on events that are of the 'right' scale. 
'What if' history clearly does suggest alternative trajectories, but the suggestion in the Manifesto seems to lean more towards using counterfactuality as a mode of drawing distinctions. There is, in any case, a burgeoning of recent literature discussing the importance of counterfactual history, in which the plausibility of the selection of historical changes is placed at the fore. If historical alternatives are grounded in probability they are deemed to be 'good reasoning'. If not, they are not (Bunzl 2004, p. 845). Ultimately, coincidence in one form of the other lies at the basis of these 'imagined' historical developments. Something in the past needed to have gone differently. But the emphasis seems less on the importance of that 'coincidence' than on the plausibility of the counterfactual consideration: how likely is it that something would have gone differently. History may not be predetermined, but randomness is still kept in check. Coincidence has its role, but is not used as an interpretive tool.

\section{Coincidence and the Construction of a Clear Course of History}

As stated above, at least some of the historians promoting counterfactual thinking, and emphasising the importance of contingency in an 'accidental view of history', did so in reaction to a determinist perspective. One of the 'determinist' views that leaves least scope for chance is the one that sees historical events as the result of divine providence. As formulated in the late-nineteenth century: 'History, when written rightly, is but a record of Providence; and he who would read history rightly, must read it with his eyes constantly on God' (Read 1862, p. 4). Very few historians, none taken seriously, would now present an academic historical analysis in such stark terms. Yet, there is still a noticeable absence for coincidence as a real factor in interpreting history among the various approaches that look at the larger schemes of history, ranging from speculative philosophy of history to macro-historical explanations and long-term causes.

Speculative philosophy of history is in a way similar to Read's notion of 'a record of Providence'. The ultimate trajectory is considered a given, and the process is then interpreted in historical terms. Thus, Hegelian dialectics assume that history follows a specific trajectory, through 'thesis' (historical developments) and the resulting 'antithesis' (historical reaction) to synthesis until history fulfils itself. In that sense: 'world history exhibits nothing other than the plan of providence' (Hegel 1807/1977). Hegel, as opposed to Read, might still be able to accept that chance occurrences were part of history, and will have influenced the lives of historical individuals over the course of time. These occurrences, however, were not significant in the greater scheme of things. They do not fit the size of the framework in which he places his historical narrative. Hegel's large-scale path of history is inevitable, and though it allows for coincidences to have happened, coincidence as a concept is excluded as a relevant mode of interpretation.

In fact, all forms of history run some risk of taking a determinist point of view in that too often an historical argument is geared towards the known outcome of a 
historical process. In the famous dictum by Schlegel: 'Der Historiker ist ein rückwärts gekehrter Prophet'. In its extreme form, this way of working leads to so-called 'Whig history' in which the present is seen as the inevitable (and desirable) outcome of historical progress. Such a presupposition results in loosing track of roads not taken or dead ends. ${ }^{8}$ The risk of falling in that methodological trap seems to be larger when the scope of the historical argument is wider. Applied at a cosmic scale, this appears to be at the basis of the so-called 'Fine Tuning Argument', debunked by Landsman in his contribution to this volume.

There have of course been (and still are) nuanced, and influential, interpretations of history by historians that focus on the structuring factors of human behaviour through the ages. Best known, and a school of thought to which the likes of Popper and Berlin reacted, is Marxism. Interestingly enough, Marxism is not prominent in current discussions on determinism in analytical philosophy. It does, however, feature with near inevitability in debates regarding macro-historical scholarship (Adcock 2007, p. 351-2). Following Popper's criticisms, Marxism (much like the 'speculative philosophies' of the likes of Hegel or Spengler) is sometime described as a form of 'historicism', which is then presented as an inflexible method of predicting the 'future course of human history'. The term 'historicism' is, however, more commonly associated with the notions of the famous nineteenth-century historians Ranke and Humboldt, in which the historical notions are in continuous flux. Historical ideas and historical developments define the nature of institutions or states and are the historicists object of study (Ankersmit 1995, p. 143; Vogt 2011, pp. 367-92 and 495-502). To avoid confusion, this chapter will avoid the massive debates about the different sorts of historicism, and formulate the argument in a context of determinism and macro-history.

It is important to note the difference in the deterministic aspects of Marxist scholarship, and the absolute 'hand of god', and slightly less absolute Hegelian dialectics, with which this section opened. Marxist views of history, in a simplified form, assert that there is an inevitable sequence within societies ('social formations') which depends on inter linkage between 'modes of productions' (economic systems) and internal conflicts ('contradictions') (Burke 1992, pp. 141-4). This certainly implies economic determinism; the notion that economic causes determine human events, or at least have a primary role in explaining outcomes. Such mono-causal explanations of historical events are looked at with suspicion by most modern historians, which partly explains the bogey-man role Marxism has come to play for those arguing against determinist points of view. Does Marxist theory also imply historical determinism? Much, as always, depends on definition:

When unpacked more fully this belief [historical determinism] is usually interpreted as a substantive claim that the aggregate course of major historical events traces a structured process of successive changes unfolding inevitably through the events of the past, present, and onto the future (Adcock 2007, pp. 352-4).

\footnotetext{
${ }^{8}$ F. V. Schlegel, Athenaeum 1798.2, 20: 'The historian is a prophet looking backwards'. Whig history: Mayr (1990). The term 'Whig history' was coined by Butterfield (1931). A recent contribution on coincidence in history, discussed further below, stresses the importance for historians to keep an open mind regarding the course history did not take: Nijhuis (2003).
} 
This excludes the possibility that coincidence influences the ultimate-inevitable - course of history.

Marxism's certainty that civilization will progress from primitive communism to the rise of private property and the development of an aristocracy, and then through feudalism and capitalism to true socialism/communism fits that definition of historical inevitability. Yet Marxism leaves scope for (temporary) developments that do not fit its pattern of history, such as the 'refeudilization' of Spain and Italy, and for individual actions or exogenous explanations to decide the pace if not the course of history. Coincidence, in these contexts, is possible and may influence the course of history. Within a smaller scale of analysis, 'coincidence' is deemed acceptable. But it does not influence the outcome of the large-scale historical process. As an explanatory notion it is irrelevant for the clear course of historical developments that are at issue in Marxist (historical) thinking (Burke 1992, pp. 141-2).

Is the exclusion of coincidence as a 'historical tool' from such large views of history inevitable? Elsewhere in this volume, De Kroon and Jongejans set out how, when looking at the complexities of ecosystems, the scale of organisation is a crucial factor in distinguishing between developments that appear unpredictable or determined. Possibly, the same applies to the study of historical 'systems'. Popper's and Berlin's sustained attack on Hegel and Marx, combined with the economic determinism in Marxist theory and its resulting mono-causality, has made the mere mention of historical determinism suspect. Yet, already half a century ago Ernst Nagel countered many of Berlin's objections to determinism as such. The central philosophical premise of determinism - every human event is the effect of antecedent causes - does not, he held, necessarily imply a claim about inevitably structured patterns in history as a whole (Nagel 1966). In fact, historical narratives can easily be construed as a sequence of events, in which specific actions were the trigger for subsequent events. Tracing a 'series of causal mechanics' can form the basis of relevant historical explanations (Hedström and Swedberg 1998). With relative frequency, recent attempts at macro-historical explanations of the past have been criticised 'for displaying unjustified determinism'. Yet macro-history (or even determinism) is not in itself incompatible with explanations that include causal complexity or choice. Like we saw in this contribution so far, and was made clear in the contribution of De Kroon and Jongejans, much depends upon the level at which we are analysing (or narrating) the historical system:

Truly stochastic (i.e. unpredictable) dynamics may find their origin in underlying deterministic processes, while stochastic interactions at a local scale may give rise to relatively stable (and hence predictable) dynamics at a global scale.

Even contingency, it seems, can be included in a macro-historical approach, if contingency effectively means contingent upon causes that cannot be explained by current theory (Adcock 2007, p. 347; pp. 354-5). So it seems that there is theoretically nothing that blocks a macro-historical approach that incorporates contingency, if not perhaps coincidence, as an interpretive framework.

Indeed, the History Manifesto, which, as we have already seen, advocated the use of counterfactual thinking among historians, also makes a bold statement for the 
return of 'grand sweeps of history', emphasising the importance of larger historical models-Braudel's longue durée-for modern society. Yet it warns that the timescale should still be such 'that historians can do what they what they do best: comparing different kinds of data side by side'. Only then can multiple causality be stressed, showing that 'the reality of natural laws' nor 'the predominance of pattern' is ultimately decisive. Individuals can choose (Guldi and Armitage 2014, pp. 5260). Historical events may be decided by such complex combinations of causes that 'contingency' should be incorporated in an historical analysis. Still, looking at historical developments in the longest-term perspective raises the risks of losing sight of contingency. As famously set out by A.J.P. Taylor: 'every road accident is caused, in the last resort, by the invention of the internal combustion engine and by men's desire to get from one place to another... But a motorist, charged with dangerous driving, would be ill-advised if he pleaded the existence of motor cars as his sole defence' (Taylor 1961, pp. 102-3, paraphrased by Guldi and Armitage 2014, p. 57).

\section{Coincidence, Big History and Accidental Cause}

Scale, it seems, is a relevant if not necessarily decisive factor in the extent to which coincidence can be included in an analysis of historical processes. At the same time, we have seen the Manifesto's plea to reclaim the telling of large historical narratives as a skill for professional historians. That attempt has much to do with the influence of discussions about human history by non-historians. Prime among them is Jared Diamond. Diamond (2005) is mentioned by Guldi and Armitage (2014), 57 as 'a gripping account of the fates of societies stricken by plague, mixing archaeological evidence with the history of species extinction and ethnic deracination', though it is simultaneously noted that the work lacks the engagement with detail that characterises the works of some recent historians. More influential than Diamond (2005) is Diamond (1997). ${ }^{9}$ It is a key example of a successful account of long-term historical processes. But it is not written by a historian, nor does it refer to writings by historians. The time-scale, also, is wholly different. Where the largest scope of a macro-historical analysis by a historian focuses on 3,000 years, Diamond's 'big history' covers more than 13,000 years. ${ }^{10}$

At the core of Diamond's book lies the theory that the main reason for Eurasian dominance in history has to do with environmental advantages. Physical geography

\footnotetext{
${ }^{9}$ This book has amassed prizes (amongst which the Pulitzer and the Aventis Prize), sold in enormous numbers, and was filmed by National Geographic. It has become so well-known that Mitt Romney attempted to use the book to support one of his claims in the 2012 American presidential campaign, which led to a published reaction by Diamond in the New York Times, followed by a host of tweets and articles: http://www.nytimes.com/2012/08/02/opinion/mittromneys-search-for-simple-answers.html, visited on 20.3.2015.

${ }^{10}$ The term 'Big history' was coined by Christian (2004).
} 
underlies historical developments. In Diamond's own words, European historical dominance resulted from

accidents of geography and biogeography - in particular to the continent's different areas, axes, and suites of wild plant and animal species. This is, the different historical trajectories of Africa and Europe stem ultimately from differences in real estate (Diamond 1997, p. 401). ${ }^{11}$

The book is well written and an extremely rewarding read, but its very strong reading of historical processes and near-negation of human agency has led to continuous critical reactions. One returning feature in that criticism is Diamond's exclusion of cultural autonomy. The environmental historian J. R. McNeill formulated his objections to this emphatically, in an exchange of views with Diamond in the New York Review of Books (May 15, 1997)

Much more powerfully than any other species, [humans] change the environment around us; and have done so ever since our ancestors began to control fire and to use tools. Learned behavior, channeled along innumerable different paths by divergent cultures, is what allows us to do so. Human beings do indeed often "approach limits imposed by environmental constraints" only to find a way to overcome and escape those constraints, as the history of technology repeatedly illustrates. ${ }^{12}$

A second, related, point of criticism is that of the book's apparently linked geographic and historical determinism:

At its worst, it develops an argument about human inequality based on a deterministic logic that reduces social relations such as poverty, state violence, and persistent social domination, to inexorable outcomes of geography and environments (Correia 2013, p. 1).

One can discuss the merits of and problems with Guns, Germs and Steel at length. For the purposes of this article, however, it is especially interesting to compare the outlook of history in the book to that of Marxism as discussed above, and note the reactions by professional historians. Marx's economic determinism fed a form of historical determinism, leading to critical reactions by historians both because of the mono-causal explanation of the course of history, and because of the absence of human agency. Replace 'economic' with 'geographic' and the outline of argument and reaction is the same for Guns, Germs and Steel, again an approach to history written by a non-historian. The comparison goes awry at several levels, but both theories deny coincidence the power to influence the outcome of historical trajectories. Diamond's dialogue with McNeill is telling:

\footnotetext{
${ }^{11}$ Note how, in some ways, Diamond seems to work from a 'first cause', the existence of which is not further explained. The underlying geographies of the world are, in Diamond's own words: 'accidents'. This is, however, a very different mode of using coincidence as an instrument in historical analysis than the one this chapter is interested in.

${ }^{12} \mathrm{http}: / /$ www.nybooks.com/articles/archives/1997/jun/26/guns-germs-and-steel/, visited on 20.3. 2015.
} 
Yet the emergence of such [literate] societies in Eurasia was no accident. It had long antecedents with clear environmental causes ... over the hundreds of generations of post-Ice Age human history, and over a large continent's thousands of societies, cultural differences become sifted to approach limits imposed by environmental constraints. ${ }^{13}$

Clear courses of history seem to leave little room for coincidence as an interpretative tool—and even less so if human agency is excluded.

\section{Coincidence and Cliodynamics}

Not all large-scale narratives of human history exclude the importance of agency or coincidence. Yet there is an inherent tension between the drive towards explaining long-term dynamical processes in history and attention to individual human actions. This comes clearly forward in the recently developed school of thought called Cliodynamics, consisting mainly of sociologists with an historical interest. Its agenda is to recognise 'laws of history':

Cliodynamics (from Clio, the muse of history, and dynamics, the study of temporally varying processes) is the new transdisciplinary area of research at the intersection of historical macrosociology, economic history/cliometrics, mathematical modeling of long-term social processes, and the construction and analysis of historical databases ... ultimately the aim is to discover general principles that explain the functioning and dynamics of actual historical societies. ${ }^{14}$

Unsurprisingly, 'coincidence' does not feature in 'Cliodynamic' scholarship, into which some of the recent scholarship of Jared Diamond might also be included (Diamond and Robinson 2010, with Thomas 2010). What Cliodynamics aims at are general principles, explaining how historical societies developed and functioned. Binding the various scholarship within this new subdiscipline of historical sciences is (1) attention for the general principles that explain the dynamics of societies, that lead to (2) models, often formulated in mathematical terms, which are the confronted with (3) empirical content. The data from historical societies are used to develop general patterns, and test the accuracy of assumption from the models. Data from (other) historical societies can then be used to test the model predictions. The basic assumption is that history can be modelled, and that these models can help us 'predict' what happened in individual societies (Turchin 2011).

At first sight, attempts to discover 'laws of history' would seem to side with the above-discussed systems of deterministic history. The much more specific attention to modelling in this new approach to large-scale historical processes, however, allows randomness to be systematically incorporated into thinking about these historical processes. In brief, the main purpose of Cliodynamic scholarship is to

\footnotetext{
${ }^{13} \mathrm{http}: / / w w w . n y b o o k s . c o m / a r t i c l e s / a r c h i v e s / 1997 / j u n / 26 / g u n s-g e r m s-a n d-s t e e l /$, visited on 20.3 . 2015.

${ }^{14}$ http://cliodynamics.info/.
} 
develop a highly sophisticated model to describe historical societies. The model includes a range of (competing) general principles that are 'translated' into systematic regularities, which can then be described as 'structural events'. Some of these events are predictable and can be modelled. Some events cannot. Which is where randomness comes in.

In the terms just described, randomness is a modelling device. There are developments and actions that are excluded from the model, in order to make events understandable. The reason to exclude them can be because the actions cannot be predicted (because, for instance, they follow from the human free will), or because the predictable causes behind the actions are unknown to the scholar designing the model, or, finally, because these causes are known but too complex for the model. The absence of these actions from the model does not deny that both structural and non-structural forces are continuously operating within societies and should be included in a perfect model. But describing the unknowable/unknown/too complex aspects of historical processes as 'random' allows the model to function, and gives the scholar possibilities to differentiate between structural forces and factors that are now described as random. Almost all authors working within this framework define human agency as 'random' (Goldstone 2003; Skocpol 2003).

The underlying assumption is one of complex causality, in which there is differentiation between structural causes and triggering events. In terms of the model, these triggering events might be 'random', but that does not deny them their place of importance. These triggering events are, however, difficult to predict. The underlying 'macro-causes' amplify these triggering notions ('micro-causes'), in which agency is crucial. Agency is essential, but not really what this field of study is particularly interested in. Instead, the structural causes underlying the effects of the triggering events are focus of attention. Randomness is accepted, but the interest is in the grand 'mechanisms' of societal change (Turchin 2006). Coincidence is not really denied, but it is certainly pushed to the background. There seems to be little attention to the role of coincidence in history when non-historians pose the questions - and it is certainly not used as a mode of interpretation.

\section{Coincidence as an Interpretative Tool?}

Might there be a mode to include coincidence as an interpretative tool in historical research, in light of the above brief overview? It seems clear that if such a notion can be used, it should give sufficient attention to so-called micro-causes, in which human agency is of great importance. Individuals have freedom to take specific actions. They of course do so within socio-biological frameworks (see the contributions by Weitzel and Rosenkranz and Van Elk, Friston and Bekkering) and within the context of a larger historical frameworks, which is what macro-history focuses on. However, as Ton Nijhuis recognised in a stimulating recent contribution on exactly this topic - coincidence in history - the action chosen out of a range of possible courses of action has influence on historical developments, and needs to be 
taken seriously. History was not a closed trajectory before it happened, and the outcome that we happened to arrive at is not necessarily more worthwhile because this is the course events took. Nijhuis draws the analogy between studying history and walking in an unknown landscape. If you only look at the trodden path, you fail to see the various avenues that you can take, and others could have taken (Nijhuis 2003 , p. 63). In a macro-historical perspective, developments are homogenous and continuous. In reality, there are heterogeneous and discontinuous serial events, that only the analysis of micro-history can make visible. In this context both Isaiah Berlin and the well-known Italian historian Carlo Ginzburg have used Tolstoy's War and Peace as an example. Tolstoy assumed that 'a historical phenomenon can become comprehensible only by reconstructing the activities of all the persons who participated in it' (Ginzburg et al. 1993, p. 24; Berlin 1978). In the intersection between private actions and the public world, history develops. For a systematic recognition of the role of coincidence in history, our analysis needs to be at the right scale. It needs to value human agency, and the stochastic element this brings into historical developments, whilst at the same time identifying the underlying processes which may be much more predictable.

The ideal historical account should take both into consideration, going back and forth between the large processes that are likely to lead to certain trajectories, and the enormous number of micro-causes that triggered the events as they happened. In that context, one might be able to usefully employ the famous thought experiment of the evolutionary biologist Stephen Jay Gould:

I call this experiment "replaying life's tape": You press the rewind button and, making sure you thoroughly erase everything that has actually happened, go back to any place in the past ... Then let the tape run again and see if the repetition looks at all like the original. ${ }^{15}$

Gould's work has been intensely discussed (and occasionally maligned), but the metaphor of replaying the tape might be a way of coming to grips with the relation between coincidence as an interpretive tool and discussion on the size of history. How likely do we deem certain historical events if they were to be played out again? To what extent does that depend on the scale of the historian's narrative? How often would Antony's distraction with Cleopatra's nose lead him to lose the battle at Actium if we were to reply the events of 2 September 31 BC? Would it be in the region of 2 out of 10.000 times (a contingent chain of events) or 9998 out of 10.000 (quasi-determined)? And might the result be different depending on our perspective? If we were to replay the whole year $31 \mathrm{BC}$, or the longer period of 44 $31 \mathrm{BC}$, would that decrease the likelihood that this chain of events were to happen again? This could be a way to start recognising the possible role of coincidence in various 'triggering events'. Coincidence might fall outside of the interpretative toolbox of the sociologists and macro-historians who are looking for a comprehensive view of historical processes, but could still play a proper role in thinking

\footnotetext{
${ }^{15}$ Gould (1989), 48, with the discussion in Vogt, Kontingenz und Zufall, 231-234. The possibilities of using Gould's thoughts for my argument, and their possible repercussions in this context, were kindly pointed out to me by Robert-Jan Wille.
} 
about historical trajectories. Not 'what if' history exactly, but rather history with an open mind.

Acknowledgment I am grateful to Remieg Aerts, Chiel van den Akker, Jelle Goeman, Klaas Landsman, Pieter Muysken and Robert-Jan Wille for comments on earlier versions of this paper, and to Peter Turchin for being willing to explain and discuss some of the underlying notions of Cliodynamics. None of them necessarily agree with the articles as it stands, but they have been extremely generous with their ideas, and massively improved the argument that I am trying to make.

Open Access This chapter is distributed under the terms of the Creative Commons Attribution-Noncommercial 2.5 License (http://creativecommons.org/licenses/by-nc/2.5/) which permits any noncommercial use, distribution, and reproduction in any medium, provided the original author(s) and source are credited. The images or other third party material in this chapter are included in the work's Creative Commons license, unless indicated otherwise in the credit line; if such material is not included in the work's Creative Commons license and the respective action is not permitted by statutory regulation, users will need to obtain permission from the license holder to duplicate, adapt or reproduce the material.

\section{References}

Adcock, R. (2007). Who's afraid of determinism? The ambivalence of macro-historical enquiry. Journal of the Philosophy of History, 1, 346-364.

Ankersmit, F. (1995). Historicism: An attempt at synthesis. History and Theory, 34, 143-161.

Berenson, B. (1952). Rumour and Reflection: 1941: 1944. London: Constable.

Berlin, I. (1954/2012). Historical inevitability (OUP Oxford) (pp. 119-190) (Reprinted in The proper study of mankind: An anthology of essays). Springer: Random House 2012.

Berlin, I. (1978). The hedgehog and the fox: An essay on Tolstoy's view of history. In: H. Hardy \& A. Kelly (Eds.), Russian Thinkers (pp. 22-81). London: Weidenfeld \& Nicolson.

Booth, C. (2003). Does history matter in strategy? The possibilities and problems of counterfactual analysis. Management Decision, 41, 96-104.

Bunzl, M. (2004). Counterfactual history: A user's guide. The American Historical Review, 109, 845-858.

Burke, P. (1992). History and social theory. Ithaca: Cornell University Press.

Bury, J. B. (1916/1930). 'Cleopatra's nose', RPA Annual (pp. 16-23) (Reprinted in J. B. Bury, Selected Essays, pp. 60-69). Cambridge: Cambridge University Press 1930.

Butterfield, H. (1931) The whig interpretation of history. London: Bell.

Carr, E. H. (1961). What is history. London: Penguin.

Christian, D. (2004). Maps of time. An introduction to big history. Berkeley: University of California Press.

Correia, D. (2013). F**k Jared diamond. Capitalism Nature Socialism, 24, 1-6.

Cushing, J. T. (1992). Historical contingency and theory selection in science. PSA: Proceedings of the Biennial Meeting of the Philosophy of Science Association, 446-457.

Diamond, J. (1997). Guns, germs and steel. The fates of human societies. New York: W.W. Norton.

Diamond, J. (2005). Collapse: How societies choose to fail or succeed. New York: Viking Press.

Diamond, J., \& Robinson, J. A. (Eds.). (2010). Natural experiments of history. Cambridge, MA: Belknap Press.

DuPont Chandler, A. (2004). Luck and the shaping of a historian's professional education. Massachusetts Historical Review, 6, 1-20. 
Elliott, J. H. (1991). Richelieu and Olivares. Cambridge: Cambridge University Press.

Elliott, J. H. (2012). History in the making. London: Yale University Press.

Evans, R. (2014). Altered pasts: Counterfactuals in history. Brown: Little.

Ferguson, N. (1997). Virtual history: Alternatives and counterfactuals. London: Picador.

Gallagher, C. (2011). What would Napoleon do? Historical, fictional, and counterfactual characters. New Literary History, 42, 323-325.

Ginzburg, C., Tedeschi, J., \& Tedeschi, A. C. (1993). Microhistory: Two or three things that I know about it. Critical Inquiry, 20, 10-35.

Goldstone, J. A. (2003) Comparative historical analysis and knowledge accumulation in the study of revolutions. In J. Mahoney \& D. Rueschmeyer (Eds.), Comparative historical analysis in the social sciences (pp. 41-90). Cambridge: Cambridge University Press.

Gould, S. J. (1989). Wonderful life: The burgess shale and the nature of history. New York: W.W Norton.

Guldi, J., \& Armitage, D. (2014). The History Manifesto. Cambridge: Cambridge University Press.

Hacker, B., \& Chamberlain, G. B. (1981). Pasts that might have been: An annotated bibliography of alternative history. Extrapolation, 22, 334-368.

Hedström, P., \& Swedberg, R. (Eds.). (1998). Social mechanisms: An analytical approach to social theory, studies in rationality and social change. Cambridge: Cambridge University Press.

Hegel, G. F. (1807/1977). Phenomenology of spirit (A. V. Miller Trans. The original Phänomenologie des Geistes, 1807). Oxford: Oxford University Press 1977.

Huizinga, J. (1937). De wetenschap der geschiedenis: Groei van de historische wetenschap sedert het begin der negentiende eeuw. In Geschiedwetenschap/hedendaagse cultuur (pp. 104-172). Haarlem: H.D. Tjeenk Willink \& zoon.

Kern, K., \& Brown, K. (2001). Using the list of creepy coincidences as an educational opportunity. The History Teacher, 34, 531-536.

Mayr, E. (1990). When is historiography Whiggish? Journal of the History of Ideas, 51, 301-309.

McClellan, J. E., III (2005). Accident, luck and serendipity in historical research. Proceedings of the American Philological Society, 149, 1-21.

Meyer, E. (1901). Geschichte des Altertums. Dritter Band: Das Perserreich und die Griechen. Erste Hälfte: Bis zu den Friedensschlüssen von 448 und 446 v. Chr. (Stuttgart).

Morello, R. (2002). Livy's Alexander digression (9.17-19): Counterfactuals and apologetics. Journal of Roman Studies, 92, 62-85.

Nagel, E. (1966). Determinism in history. In W. Dray (Ed.), Philosophical analysis and history. New York: Harper \& Row.

Nijhuis, T. (2003). Geschiedenis, toeval en contigentie. In S. Haakma \& E. Lemmens (Eds.), Toeval (PP. 49-72). Utrecht: Studium Generale.

Post, R. C. (2009). Chance and contingency: Putting Mel Kranzberg in context. Technology and Culture, 50, 839-872.

Read, H. (1862). The hand of god in history: Or, divine providence historically illustrated in the extension \& establishment of christianity. Glasgow: W. Collins.

Ringer, F. (2002). Max weber on causal analysis interpretation and comparison. History and Theory, 41, 163-178.

Skocpol, T. (2003). Doubly engaged social science: The promise of comparative historical analysis. In J. Mahoney \& D. Rueschmeyer (Eds.), Comparative historical analysis in the social sciences (pp. 407-428). Cambridge: Cambridge University Press.

Squire, J. C. (1931). If it had happened otherwise. Greens: Longmans.

Taylor, A. J. P. (1945). The course of German history, a survey of the development of German history since 1815. London: Hamish Hamilton.

Taylor, A. J. P. (1961). The origins of the Second World War. London: Hamish Hamilton.

Thomas, C. E. (2010). 'Test in Time', Cliodynamics, 1 (2010). Retrieved from http://escholarship. org/uc/item/368956r6. 
Thompson, W. (2010). The lead economy sequence in world politics (from Sung China to the United States): Selected counterfactuals. Journal of Globalization Studies, 1, 6-28.

Trevelyan, G. M. (1918). From Waterloo to Marne. Quartely Review, 229, 73-90.

Turchin, P. (2006). War and peace and war: The life cycles of imperial nations. NY: Pi Press.

Turchin (2011). Social tipping points and trend reversals: A historical approach. Presented at the Tipping Point Workshop May 20-22. Switzerland: Mount PilatusLucerne.

Vogt, P. (2011). Kontingenz und Zufall. Eine Ideen- und Begriffsgeschichte Berlin: Akademie Verlag.

Weber, M. (1905). Objective possibility and adequate causation in historical explanation. In M.

Weber, E. Shils \& H. Finch (Eds.), The methodology of the social sciences (pp. 164-88).

Glencoe: Free Press 1949 (original 1905). 